\title{
The neuraminidase gene is present in the non-toxigenic Vibrio cholerae Amazonia strain: a different allele in comparison to the pandemic strains
}

\author{
Sonia Catarina de Abreu Figueiredo/ ${ }^{*}$, Anna Cristina Neves-Borges $/{ }^{++}$, Ana Coelho/ ${ }^{+}$
}

Departamento de Genética, Instituto de Biologia *Departamento de Clínica Médica, Faculdade de Medicina, Universidade Federal do Rio de Janeiro, Av. Pau Brasil 211, Bloco A, s. A2-105, Ilha do Fundão, 21944-970 Rio de Janeiro, RJ, Brasil

The neuraminidase gene, nanH, is present in the O1, non-toxigenic Vibrio cholerae Amazonia strain. Its location has been assigned to a $150 \mathrm{~kb}$ NotI DNA fragment, with the use of pulsed-field gel electrophoresis and DNA hybridization. This NotI fragment is positioned inside $630 \mathrm{~kb}$ SfiI and $1900 \mathrm{~kb}$ I-CeuI fragments of chromosome 1. Association of the pathogenicity island VPI-2, carrying nanH and other genes, with toxigenic strains has been described by other authors. The presence of nanH in a non-toxigenic strain is an exception to this rule. The Amazonia strain nanH was sequenced (Genbank accession No. AY825932) and compared to available V. cholerae sequences. The sequence is different from those of pandemic strains, with 72 nucleotide substitutions. This is the first description of an $\mathrm{Ol}$ strain with a different nanH allele. The most variable domain of the Amazonia NanH is the second lectin wing, comprising 13 out of 17 amino acid substitutions. Based on the presence of nanH in the same region of the genome, and similarity of the adjacent sequences to VPI-2 sequences, it is proposed that the pathogenicity island VPI-2 is present in this strain.

Key words: Vibrio cholerae - Amazonia strain - neuraminidase - sialidase - nanH - pathogenicity island

Vibrio cholerae is a Gram-negative bacterium that lives in aquatic environments, often associated with plankton and other marine organisms (Colwell et al. 1977). Although more than 200 serogroups of $V$. cholerae have been identified, only a few (O1 and O139) are related to epidemic human disease (Glenn Morris et al. 1994). These pathogenic strains have acquired the capacity to survive adverse conditions in the host, and to multiply in the human small intestine, after ingestion of contaminated food and water. They are released through feces in the water, in a highly infectious stage (Merrell et al. 2002), and survive in the aquatic life cycle.

$V$. cholerae is the etiological agent of cholera, a severe diarrheal disease, with high morbidity and mortality, if left untreated (Sack et al. 2004). The disease is characterized by voluminous watery stools, dehydration, and hypovolemic shock. Cholera occurs in outbreaks, frequently affecting whole countries, and seven pandemics have been recorded (Barua 1992). The ongoing seventh pandemics started in 1961 in Indonesia, and reached Latin America in 1991, after a century of absence of reported cholera cases in this continent.

Although there are no known absolute markers that define epidemic strains, as a general rule they produce both the cholera toxin (CT) and toxin-regulated pilus (TCP) (Faruque et al. 1998). The bacteria adhere and

Financial support: CNPq, Faperj, Capes, FUJB (Brasil) This work is part of the $\mathrm{PhD}$ research of SCA Figueiredo. ${ }^{+}$Corresponding author. E-mail: coelho@biologia.ufrj.br

${ }^{++}$Fellowship Faperj

Received 16 June 2005

Accepted 31 August 2005 colonize the epithelium of the small intestine by means of the TCP, and release CT in the vicinity of their target cells (Lee et al. 1999). Genes encoding CT reside in the lysogenic phage CTXФ, and those encoding products for the biosynthesis of TCP constitute a pathogenicity island, VPI (Waldor \& Mekalanos 1996, Karaolis et al. 1998). The main virulence-related factors of $V$. cholerae are thus encoded on mobile genetic elements, probably acquired via horizontal gene transfer (Faruque \& Mekalanos 2003).

Cholera in Latin America was caused by a seventh pandemic El Tor strain (Salles et al. 1993, Tauxe et al. 1994). Probably due to increased surveillance during the first epidemic year in Brazil, other V. cholerae were isolated from patients with cholera symptoms. One particular new strain was described from a localized outbreak, and denominated the Amazonia strain (Coelho et al. 1995). V. cholerae Amazonia is an O1, non-toxigenic strain, isolated from more than 20 patients. It is strongly hemolytic, but other virulence factors such as TCP, zonula ocludens toxin, and thermo-stable toxin ST are absent (Coelho et al. 2000).

$V$. cholerae neuraminidase, a sialidase, is also considered a virulence factor (Staerk et al. 1974, Galen et al. 1992). Sialidases are found mainly in higher eukaryotes, and also in some microorganisms (Roggentin et al. 1993). V. cholerae neuraminidase (EC 3.2.1.18) releases sialic acid from higher gangliosides present on eukaryotic cells surface, exposing ganglioside GM1, which is the cholera toxin receptor (Holmgren et al. 1975). Recently, Jermyn and Boyd (2002) showed that the neuraminidase gene, $n a n H$, is present inside a region fulfilling all the criteria to be considered a pathogenicity island. They named this new island as VPI-2, and showed that it is present in its original version in toxigenic strains, being absent in nontoxigenic strains, and present in modified versions in $\mathrm{O} 139$ epidemic strains, and also in the sister species V. mimicus (Jermyn \& Boyd 2002, 2005). 
In this paper we report the presence of $n a n H$ in $V$. cholerae Amazonia, sequence the whole gene, compare it to nucleotide and amino acid sequences available for this gene, and map it to a $150 \mathrm{~kb}$ NotI fragment of chromosome 1 , and the corresponding genomic fragments with the SfiI and I-CeuI enzymes.

\section{MATERIALS AND METHODS}

Bacterial strains and media - V. cholerae strains used in this study are shown in Table I. Cultures were started from frozen stocks using Luria-Bertani (LB) broth in a rotary shaker at $37^{\circ} \mathrm{C}$.

Chromosomal DNA preparations and pulsed-field gel electrophoresis (PFGE) - Bacterial cells in late-logarithmic phase of growth were embedded in low-melting agarose plugs (USB), lysed and treated for DNA preparation essentially as previously described (Maslow et al. 1993). In-gel digestions were performed using standard protocols with the enzymes SfiI, NotI and I-CeuI. Pulsed-field-certified agarose (USB) was used in gels in $0,5 \mathrm{X}$ Tris-borate-EDTA electrophoresis buffer. PFGE was carried out at $10^{\circ} \mathrm{C}$ with a Gene Navigator System (Amersham) with differ- ent pulse programs, according to the fragment sizes to be separated. Program 1: pulses from $5 \mathrm{~s}$ to $30 \mathrm{~s}$, for $22 \mathrm{~h}, 1 \%$ gels; program 2: pulses from $15 \mathrm{~s}$ to $100 \mathrm{~s}$, for $27 \mathrm{~h}, 1.2 \%$ gels; program 3, pulses from $80 \mathrm{~s}$ to $120 \mathrm{~s}$, for $40 \mathrm{~h}, 1.2 \%$ gels. Low-range PFG marker (New England Biolabs) and yeast DNA-PFGE markers (Amer-sham) were used as size markers. After electrophoresis, the gels were stained with ethidium bromide, and photographed.

Southern blots - Southern blots followed a standard procedure (Sambrook et al. 1989), including a preliminary $\mathrm{HCl} 0.25 \mathrm{~N}$ treatment, for $15 \mathrm{~min}$. Nylon membranes (Hybond-XL, Amersham) were used, and probes were radioactively labeled with ${ }^{32} \mathrm{P}-\mathrm{dCTP}$ using a random primers kit (Invitrogen). Hybridization solutions contained $50 \%$ formamide, and hybridizations were carried out at $42^{\circ} \mathrm{C}$. X-ray films (Hyperfilm, Amersham) were exposed overnight at $-80^{\circ} \mathrm{C}$ with an intensifier screen.

Primer design and PCR amplification conditions - The primers shown in Table II were used in PCR amplifications, and were designed with the use of the available genomic sequence of V. cholerae O1 El Tor strain N16961 (Heidelberg et al. 2000), and the Oligo v.4.0 software. PCRs were

TABLE I

Vibrio cholerae strains used in this study

\begin{tabular}{lll}
\hline Strain $^{a}$ & Description & Isolation \\
\hline N16961 & El Tor biotype & Bangladesh, India, 1975 \\
3439 & Amazonia strain & Tonantins, Brazil, Jan. 1992 \\
3506 & Amazonia strain & São Paulo de Olivença, Brazil, Jan. 1992 \\
3509 & Amazonia strain & São Paulo de Olivença, Brazil, Jan. 1992 \\
4008 & Amazonia strain & São Paulo de Olivença, Brazil, Apr. 1992 \\
4010 & Amazonia strain & São Paulo de Olivença, Brazil, Apr. 1992 \\
4132 & Amazonia strain & Santo Antonio do Içá, Brazil, May 1992 \\
\hline
\end{tabular}

$a$ : all the strains belong to serogroup O1. The Amazonia strains are serotype Ogawa, and were obtained from clinical sources.

TABLE II

Oligonucleotide primer pairs used in this study

\begin{tabular}{|c|c|c|c|}
\hline Name & Sequence $5^{\prime}-3^{\prime}$ & 5'-end coordinate ${ }^{a}$ & Source \\
\hline nanH-f & TTTTTACAGCGTCTATGATG & 1934298 & \multirow[t]{2}{*}{ This study } \\
\hline$n a n H-r$ & GGTTTCCTTGTGGGTTAGTA & 1935424 & \\
\hline LnanH2814f & AGCCGCCGCCACTGTATTA & 1932814 & \multirow[t]{2}{*}{ This study } \\
\hline LnanH3626r & TCCACCACTGAGCACTTTC & 1933626 & \\
\hline LnanH2407f & ATGTCGCCTTTTGAGAGTC & 1932407 & \multirow[t]{2}{*}{ This study } \\
\hline LnanH3766r & TATTCCGTTGCTGCTGTGC & 1933766 & \\
\hline nanH1359f & GGCGAATGACGACAGAAA & 1933589 & \multirow[t]{2}{*}{ This study } \\
\hline nanH2262r & CATCGGCAACTTGTATCT & 1934509 & \\
\hline nanH2784f & TCTACCCAGCGATTGTGC & 1935014 & \multirow[t]{2}{*}{ This study } \\
\hline nanH3473r & CGGTGACGAGAAATAAGC & 1935720 & \\
\hline nanH2838f & GTGATGATGGCGGTTCAA & 1935068 & \multirow[t]{2}{*}{ This study } \\
\hline nanH3953r & АТСТСТGCTGCTTCTTCC & 1936200 & \\
\hline toxT f59 & ATGATTGGGAAAAAATCTT & 899896 & \multirow[t]{2}{*}{ Baptista 2000} \\
\hline toxT r859 & AACTCCTGTCAACATAAAT & 900714 & \\
\hline
\end{tabular}

$a$ : coordinates in the El Tor strain N1696 chromosome 1, as in TIGR-CMR (http://www.tigr.org/tigr-scripts/CMR2/GenomePage3. $\mathrm{spl}$ ? database $=\mathrm{gvc})$. 
performed in $50 \mu \mathrm{l}$ volumes containing $100 \mathrm{ng}$ genomic DNA, $0.5 \mu \mathrm{g}$ of each primer, $2 \mathrm{mM} \mathrm{MgCl}{ }_{2}$ and $2.5 \mathrm{U} \mathrm{Taq}$ DNA polymerase (Biotools). The thermocycler program included an initial 5 min denaturation at $94^{\circ} \mathrm{C}$, and 35 cycles at $94^{\circ} \mathrm{C}$ for $60 \mathrm{~s}, 55^{\circ} \mathrm{C}$ for $90 \mathrm{~s}$ and $72^{\circ} \mathrm{C}$ for $60 \mathrm{~s}$.

DNA sequence analysis and comparisons - PCR products used for sequencing were purified using the GFX PCR and gel band purification kit (Amersham). Sequencing reactions were done with a DYEnamic ET dye terminator kit (Megabace) (Amersham) and applied to an automated DNA sequencing system (Megabace, Amersham). Sequences were analyzed using the Chromas software (Version 1.45, Griffith University, Qld, Australia). Comparison to the available sequences of the El Tor strain N16961 and classical strain O395 were done with the ClustalW 1.8 alignment program at the BCM Search Launcher: Multiple Sequences Alignment (http://searchlauncher.bcm.tmc. edu/multi-align/multi-align.html) and NCBI-Blast (http:// www.ncbi.nlm. nih.gov).

\section{RESULTS}

Presence of the nanH gene in the V. cholerae Amazonia genome - The presence of the nan $H$ gene in the V. cholerae Amazonia 3509 genome was established by PCR amplification. A $1.1 \mathrm{~kb}$ fragment was obtained with primers $n a n H$-f and $n a n H$-r. The size of this fragment for the Amazonia strain is the same as the El Tor predicted product. In order to verify if other isolates of the Amazonia strain also carried the gene, amplification was carried out with isolates 3439, 3506, 4008, 4010 and 4132, all with positive results (data not shown).

Chromosomal location of the nanH gene of $V$. cholerae Amazonia - The position of the $n a n H$ gene was analyzed using the techniques of PFGE and DNA hybridization, making a comparison of Amazonia strain isolate 3509 and El Tor strain N16961. NotI was chosen as a first restriction enzyme to use, as nanH is in the center of a $172.5 \mathrm{~kb}$ Not I fragment in the El Tor strain, a size easily amenable to analysis. After PFGE, the gels were transferred to nylon membranes and hybridized to ${ }^{32} \mathrm{P}$ radioactive probes. The $1.1 \mathrm{~kb}$ internal nanH Amazonia fragment was used as a probe. A hybridization control experiment was done with a strip from the same gel shown, using a toxT internal fragment, obtained with primers tox $T$ f59 and tox $T \mathrm{r} 859$, and known to be present in the El Tor strain but not the Amazonia strain.

Fig. 1a shows the NotI restriction digests of the Amazonia and El Tor strains DNA, and Fig. $1 \mathrm{~b}$ shows the result of hybridization with the $n a n H$ probe. The expected 172.5 $\mathrm{kb}$ El Tor fragment showed hybridization. In the case of the Amazonia strain, a smaller, $150 \mathrm{~kb}$ fragment hybridized to $n a n H$. Fig. 1c shows the hybridization to toxT, confirming that the Amazonia strain does not carry toxT, and detecting an $88.3 \mathrm{~kb}$ fragment for the El Tor strain, the size expected from the genome sequence.

Other enzymes were used, in order to make a better assignment of the gene position. Fig. 2a shows SfiI DNA restrictions of strains Amazonia and El Tor and hybridization to the $n a n H$ probe. It can be seen that the upper SfiI band of the Amazonia and El Tor strains hybridize to $\mathrm{nanH}$. The Amazonia band with nanH was measured as $630 \mathrm{~kb}$,

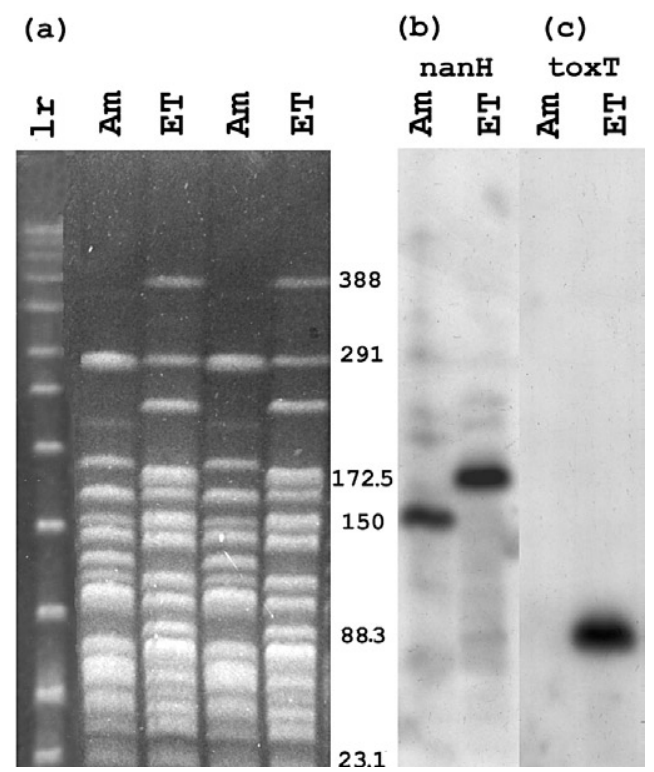

Fig. 1: pulsed-field gel and Southern blot analysis of NotI-digested chromosomal DNA of Vibrio cholerae. 1r, low-range PFG markers, Am, Amazonia strain 3509, ET, El Tor strain N16961. Program 1 was used for the PFGE (a). The gel was cut in two strips, transferred to nylon membranes and these were used in hybridizations with probes for genes $n a n H$ or toxT, detecting the presence of nanH in both strains (b), and confirming the presence of toxT only in the El Tor strain (c). The sizes of the chromosomal fragments carrying $n a n H$ are $172.5 \mathrm{~kb}$ for the El Tor strain and $150 \mathrm{~kb}$ for the Amazonia strain, as seen in filter (b). The control strip (c) shows a fragment of $88.3 \mathrm{~kb}$ carrying the toxT gene in the El Tor strain, and no hybridization with the Amazonia chromosomes.
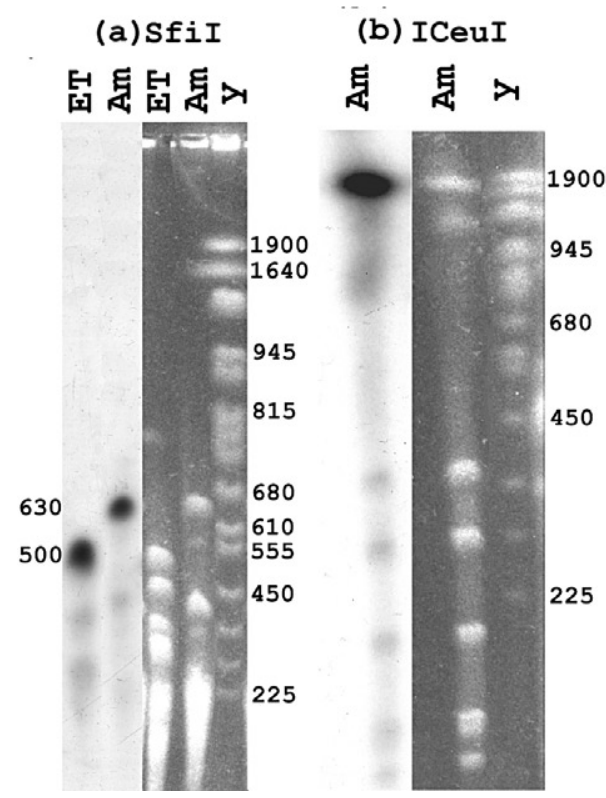

Fig. 2: pulsed-field gels and Southern blot analysis of SfiI or I-CeuIdigested chromosomal DNA of Vibrio cholerae, estimating the size of fragments carrying the $n a n H$ gene. Am, and ET as in Fig. 1, y, yeast DNA-PFGE markers. (a) Pulsed-field gel (program 3) with Sfi-digested DNA on the right panel, and on the left the corresponding autoradiogram, showing fragments of $630 \mathrm{~kb}$ and $500 \mathrm{~kb}$ hybridizing with the $n a n H$ probe for the Amazonia and El Tor strains, respectively. (b) Pulsed-field gel of I-CeuI-digested Amazonia strain DNA (program 2, right panel) and the hybridization of a $1900 \mathrm{~kb}$ fragment to the $n a n H$ probe (left panel). 
and the El Tor band as $500 \mathrm{~kb}$. The I-CeuI DNA fragments were also hybridized to $n a n H$. Fig. $2 \mathrm{~b}$ shows that a large Amazonia DNA fragment carries the $n a n H$ gene, comparable in size to the El Tor $1900 \mathrm{~kb}$ corresponding fragment (El Tor data not shown).

Sequence of V. cholerae Amazonia nanH - The DNA sequence of $n a n H$ from isolate 3509 was determined. The $1.1 \mathrm{~kb}$ PCR fragment was used, but other regions were amplified in order to cover the whole gene. Primer pairs LnanH2814f and LnanH3626r, LnanH2407f and LnanH3766r, nanH1359f and nanH2262r, nanH2784f and $n a n H 3473$ r, and $n a n H 2838$ f and nanH3953r (Table II) yielded fragments of expected sizes (approximately $813 \mathrm{pb}$, 1360pb, $921 \mathrm{bp}, 707 \mathrm{bp}$, and $1133 \mathrm{bp}$, respectively), and allowed the sequencing of the whole $n a n H$ gene (2424 bp), and the next gene, similar to El Tor VC1785 (207 bp). The
3234 bp sequence has been deposited in the Genbank, with accession No. AY825932.

nanH sequence comparison - Jermyn and Boyd (2005) proposed a molecular evolution of VPI-2 based on a comparison of a $0.7 \mathrm{~kb}$ fragment of the $\mathrm{nanH}$ sequence of various strains. With the whole sequence of nanH, it was possible to extend this analysis in the case of the Amazonia strain. Table III ( $a$ and $b$ ) shows the nucleotide and amino acid substitutions found for this allele of the gene, in comparison to the sequence of VC1784 from the El Tor strain N16961 (Heidelberg et al. 2000). The sequence for classical strain O395 is identical (Galen et al. 1992), and these strains can be taken as representative of the pandemic strains. Seventy-two nucleotide substitutions were found, with an overall substitution rate of $2.97 \%$ along the $2424 \mathrm{bp}$. They result in seventeen amino acid substitutions.

TABLE III

Nucleotide and amino acid sequence differences between El Tor and Amazonia strains

(a) Nucleotides

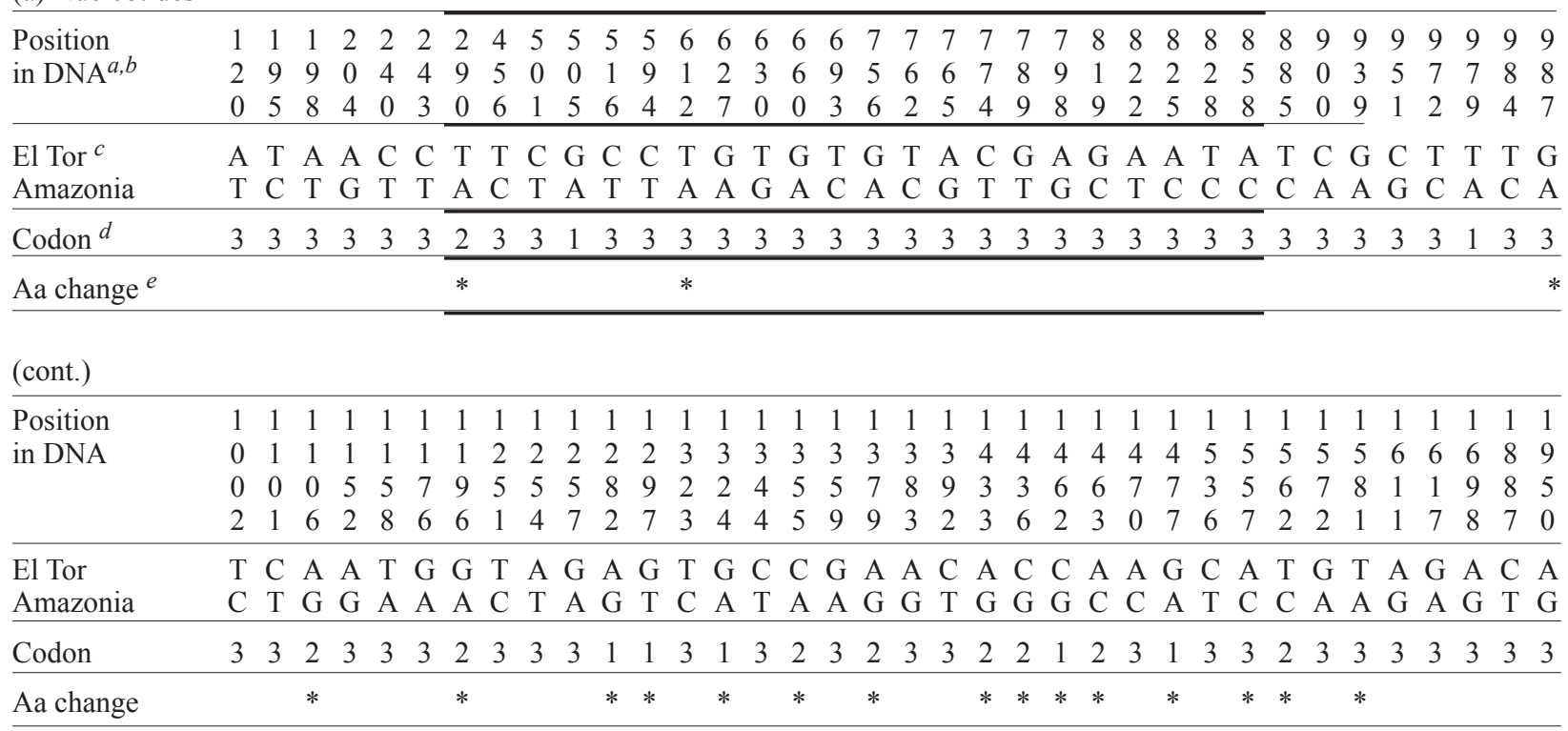

(b) Amino acids

\begin{tabular}{llllllllllllllllll}
\hline Position in protein & 9 & 1 & 3 & 3 & 3 & 4 & 4 & 4 & 4 & 4 & 4 & 4 & 4 & 4 & 5 & 5 & 5 \\
& 7 & 6 & 2 & 6 & 9 & 2 & 3 & 4 & 5 & 6 & 7 & 7 & 8 & 9 & 1 & 2 & 2 \\
& & 9 & 7 & 9 & 9 & 8 & 3 & 2 & 2 & 0 & 8 & 9 & 8 & 3 & 9 & 1 & 7 \\
\hline
\end{tabular}

El Tor I V S Q S S V G A H H T Q A K V H

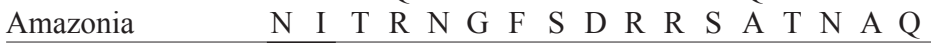

Substitution type $f_{\mathrm{N}} \mathrm{C}$ C C C N N N N N N C N N N N N

$\begin{array}{llllllllllllllllll}\text { Protein domain } g & 1 & 1 & \mathrm{p} & \mathrm{p} & 2 & 2 & 2 & 2 & 2 & 2 & 2 & 2 & 2 & 2 & 2 & 2 & 2\end{array}$

$a$ : numbers (in vertical format) correspond to nucleotide positions along the $n a n H$ gene in (a), and to amino acid positions along the NanH protein in (b), using the TIGR-CMR annotation (http://www.tigr.org/tigr-scripts/CMR2/GenePage.spl?locus=VC1784). The mature protein starts at amino acid 51 with this numbering. In order to make a correlation to the amino acid numbers in Crennel et al. (1994), decrease 26 from the given numbers in (b); $b$ : the region analyzed in Jermyn and Boyd (2005) is marked by darker borders in both tables; $c$ : El Tor strain N16961 and Amazonia strain 3509; $d$ : positions in codon; $e$ : nucleotide substitutions leading to changes in amino acids. Note that substitutions in positions 1462 and 1463 change a single amino acid; $f$ : C, conservative, and $\mathrm{N}$, non-conservative amino acid substitutions (BLOSUM 62 matrix, Henikoff \& Henikoff 1992); $g$ : NanH comprises three domains: 1 , lectin wing $1 ; \mathrm{p}, \beta$-propeller; 2 , lectin wing 2 . 


\section{DISCUSSION}

The analysis of whole genomes is leading to more insight into the flexibility of genomes, and their acquisition of a variety of genes that distinguish strains from one another, and may lead to an increased virulence of particular strains. In $V$. cholerae the two main virulence regions are examples of movable DNA, that may be acquired by other strains: the CTX $\Phi$, a lysogenic phage carrying the genes for cholera toxin, and VPI (or VPI-1), carrying genes for the TCP pilus, involved in colonization. VPI-2 was described as a new pathogenicity island of toxigenic $V$. cholerae, carrying the $n a n H$ gene for neuraminidase (Jermyn \& Boyd 2002). The presence of $n a n H$ in various isolates of the Amazonia strain, which is non-toxigenic, shows that this general association of $n a n H$ to toxigenic strains is not so strict. The DNA sequence obtained for $n a n H$, with a $2.97 \%$ difference to the El Tor strain, rules out the possibility of a nanH horizontal transfer to the Amazonia strain during the Latin American epidemic of the 1990s.

NanH is known to have other cellular roles, such as sialic acid metabolism. Sialic acid is a source of carbon, nitrogen, energy and cell wall biosynthesis (Vimr \& Troy 1985, Vimr et al. 2004). Another important role is as part of the mucinase complex. This complex contains neuraminidase, proteinases and an endoglycosidase (Stewart-Tull et al. 1986). The mucinase complex acts on the mucus gel protecting the underlying intestinal cells. The breakdown of sialomucin allows the bacteria to reach and colonize the epithelium.

$V$. cholerae Amazonia is a pathogenic strain, and these modulator or accessory virulence factors may be important for pathogenic non-toxigenic strains. There are several reports of local outbreaks of cholera caused by non-epidemic strains (Sharma et al. 1998, Cheasty et al. 1999, Pal et al. 1999). These are either O1 or non-O1 isolates, and many of these are non-toxigenic, posing a question about their virulence mechanism. The presence of additional virulence factors has been proposed. These include the non-membrane-damaging cytotoxin, Rtx toxin, hemolysins, proteases and haemagglutinins (Mitra et al. 1998, Cheasty et al. 1999, Lin et al. 1999). Colonization in itself could cause diarrhea (Kaper et al. 1994), and the presence of neuraminidase, helping colonization, may be one factor in this puzzle.

PFGE was done, to locate the $n a n H$ gene of $V$. cholerae Amazonia, comparing the position of the gene to its position in strain N16961. The N16961 strain in our laboratory originates from Dr Kaper's laboratory (University of Maryland), as is the case for the sequenced strain. Even so, we found a difference in the SfiI fragments obtained, in relation to the fragments expected from the genome sequence. The larger S $f i$ fragment found in our case is the $500 \mathrm{~kb}$ fragment, that hybridizes with $\operatorname{nanH}$ (Fig. 2a), and also to rtxA and ctxa (data not shown). We propose that one SfiI site that should be present at position 1625927 of the genome is not present in our strain, and two adjacent fragments of $89 \mathrm{~kb}$ and $411 \mathrm{~kb}$ are joined together as the largest fragment of $V$. cholerae El Tor. This El Tor SfiI fragment is located inside the largest $1900 \mathrm{~kb} \mathrm{I-CeuI} \mathrm{fragment.}$ For the Amazonia strain a I-CeuI fragment of similar gel mobility was found. A precise size assignment is difficult to make for fragments of this size. The presence of nanH into this fragment, larger than chromosome 2, places nanH into chromosome 1. In a preliminary genome map of the Amazonia strain that we are constructing, the fragments carrying nanH in the Amazonia genome, I-CeuI of 1900 $\mathrm{kb}$, SfiI of $630 \mathrm{~kb}$ and NotI of $150 \mathrm{~kb}$, correspond to the El Tor fragments of $1900 \mathrm{~kb}$ (I-CeuI), $500 \mathrm{~kb}$ (Sfil) and $172.5 \mathrm{~kb}($ NotI), respectively. The conclusion is that the position of nanH in the Amazonia strain genome is in the same region as in the El Tor strain.

$\mathrm{NanH}$ is a large neuraminidase $(83 \mathrm{kDa})$, a threedomain protein consisting of two lectin wings and a central active neuraminidase domain, formed by six $\beta$-sheets arranged as in the blades of a propeller ( $\beta$-propeller, Crennel et al. 1994, Moustafa et al. 2004). In studies with crystals of the classical strain O395 neuraminidase, some amino acids were proposed to be relevant for activity (Crennel et al. 1994), and all of these are conserved in the Amazonia strain. They include Arg250 (see footnote a to Table III concerning the numbering system used), Arg661, Arg738, Glu782, Tyr766, Glu645, Trp337, Asp276, Arg271, Asp318, Asp663, Asn344, Phe664, and Leu606. The Asp-boxes (Ser/Thr-X-Asp-[X]-Gly-X-Thr-Trp/Phe) of the $\beta$-propeller (Crennel et al. 1994) are also conserved in the Amazonia sequence.

Seventeen amino acid substitutions were found in $\mathrm{NanH}$, in comparison to the identical sequences of El Tor strain N16961 and classical strain O395 (Table IIIb). Thirteen of these are in the second lectin wing of the neuraminidase, the most variable region of the protein for the Amazonia strain. The first lectin wing is known to bind sialic acid, but the ligand for the second wing is unknown (Moustafa et al. 2004). The first wing of the Amazonia $\mathrm{NanH}$ presents only two substitutions, one of these a conservative substitution in one of the $15 \beta$-strands of the domain, and the other in a loop region. In the $\beta$-propeller active domain of the enzyme there are two conservative substitutions, one of these in one of the $24 \beta$-strands of this domain. In the second lectin wing, comprising $15 \beta$-strands and $2 \alpha$-helices, 6 of the substitutions are in $\beta$-strands (1 conservative, 5 non-conservative), 1 in an $\alpha$-helix (nonconservative), and 6 in connection loops.

Jermyn and Boyd (2005) used a $0.7 \mathrm{~kb}$ PCR fragment from various strains of $V$. cholerae and $V$. mimicus, in a study of variation of $n a n H$. A comparison of our data to the corresponding stretch analyzed in that paper shows that the Amazonia strain presents an allele 2 for $n a n H$, identical, in this region, to the allele in strain E714. The description given in that paper for this strain is incomplete, and its serogroup and isolation date are not known. The other strain with an allele 2 belongs to serogroup O8. The $\mathrm{O} 1$ and $\mathrm{O} 139$ strains studied all carry an allele 1. The Amazonia strain is the first $\mathrm{O} 1$ strain with a new allele for $n a n H$.

Taking into consideration our results for $V$. cholerae Amazonia, we propose a shift in the region of $n a n H$ to be analyzed and compared in future allele studies. Nucleotides 1105 to 1581 encompass fourteen amino acid substitutions for $V$. cholerae Amazonia, as compared to only two changes in the region analyzed for various strains (approximately 264 to 858, Jermyn \& Boyd 2005). 
In order to sequence the whole $n a n H$ gene, we had to design primers located outside $n a n H$, in nearby VPI-2 regions according to the El Tor N16961 sequence. The amplifications worked well, yielding fragments with the expected sizes. The gene located immediately to the right of nanH in the El Tor strain, VC1785, was found in the same position in the Amazonia strain. Based on the presence of the nanH gene and nearby VPI-2 regions, we propose that the Amazonia strain carries a VPI-2 region, to be detailed in further studies.

\section{REFERENCES}

Baptista MAS 2000. Caracterização Genético-molecular dos Genes Regulatórios toxR e toxS e Identificação de Outros Loci do Variante Amazônia de Vibrio cholerae em Comparação com o Genoma de Vibrio cholerae El Tor, MSc Thesis, Ciências Biológicas (Genética), Universidade Federal do Rio de Janeiro, Rio de Janeiro.

Barua D 1992. History of cholera. In D Barua, WB Greenough III (eds), Cholera, Plenum Medical Book, New York and London, p. 1-36.

Cheasty T, Said B, Threlfall EJ 1999. V cholerae non-O1: implications for man? Lancet 354: 89-90.

Coelho A, Andrade JR, Vicente AC, DiRita VJ 2000. Cytotoxic cell vacuolating activity from Vibrio cholerae hemolysin. Infect Immun 68: 1700-1705.

Coelho A, Andrade JR, Vicente AC, Salles CA 1995. New variant of Vibrio cholerae $\mathrm{O} 1$ from clinical isolates in Amazonia. $J$ Clin Microbiol 33: 114-118.

Colwell RR, Kaper J, Joseph SW 1977. Vibrio cholerae, Vibrio parahaemolyticus and other vibrios: occurrence and distribution in Chesapeake Bay. Science 198: 394-396.

Crennell S, Garman E, Laver G, Vimr E, Taylor G 1994. Crystal structure of Vibrio cholerae neuraminidase reveals dual lectin-like domains in addition to the catalytic domain. Structure 2: 535-544.

Faruque SM, Mekalanos JJ 2003. Pathogenicity islands and phages in Vibrio cholerae evolution. Trends Microbiol 11: 505-510.

Faruque SM, Albert MJ, Mekalanos JJ 1998. Epidemiology, genetics, and ecology of toxigenic Vibrio cholerae. Microbiol Mol Biol Rev 62: 1301-1314.

Galen JE, Ketley JM, Fasano A, Richardson SH, Wasserman SS, Kaper JB 1992. Role of Vibrio cholerae neuraminidase in the function of cholera toxin. Infect Immun 60: 406-415.

Glenn Morris Jr J, and the Cholera Laboratory Task Force 1994. Vibrio cholerae O139 Bengal. In IK Wachsmuth, PA Blake, Ø Olsvik (eds), Vibrio cholerae and Cholera, American Society for Microbiology, Washington, p. 95-102.

Heidelberg JF, Eisen JA, Nelson WC, Clayton RA, Gwinn ML, Dodson RJ, Haft DH, Hickey EK, Peterson JD, Umayam L, Gill SR, Nelson KE, Read TD, Tettelin H, Richardson D, Ermolaeva MD, Vamathevan J, Bass S, Qin H, Dragoi I, Sellers P, McDonald L, Utterback T, Fleishmann RD, Nierman WC, White O, Salzberg SL, Smith HO, Colwell RR, Mekalanos JJ, Venter JC, Fraser CM 2000. DNA sequence of both chromosomes of the cholera pathogen Vibrio cholerae. Nature 406: 477-483.

Henikoff S, Henikoff JG 1992. Amino acid substitution matrices from protein blocks. Proc Natl Acad Sci USA 89: 10915-10919.
Holmgren J, Lonnroth I, Mansson J, Svennerholm L 1975. Interaction of cholera toxin and membrane GM1 ganglioside of small intestine. Proc Natl Acad Sci USA 72: 2520-2524.

Jermyn WS, Boyd EF 2002. Characterization of a novel Vibrio pathogenicity island (VPI-2) encoding neuraminidase ( $\mathrm{nanH}$ ) among toxigenic Vibrio cholerae isolates. Microbiology 148: 3681-3693.

Jermyn WS, Boyd EF 2005. Molecular evolution of Vibrio pathogenicity island-2 (VPI-2): mosaic structure among Vibrio cholerae and Vibrio mimicus natural isolates. Microbiology 151: 311-322.

Kaper JB, Fasano A, Trucksis M 1994. Toxins of Vibrio cholerae. In IK Wachsmuth, PA Blake, Ø Olsvik (eds), Vibrio cholerae and Cholera, American Society for Microbiology, Washington, p. 145-176.

Karaolis DK, Johnson JA, Bailey CC, Boedeker EC, Kaper JB, Reeves PR 1998. A Vibrio cholerae pathogenicity island associated with epidemic and pandemic strains. Proc Natl Acad Sci USA 95: 3134-3139.

Lee SH, Hava DL, Waldor MK, Camilli A 1999. Regulation and temporal expression patterns of Vibrio cholerae virulence genes during infection. Cell 99: 625-634.

Lin W, Fullner KJ, Clayton R, Sexton JA, Rogers MB, Calia KE, Calderwood SB, Fraser C, Mekalanos JJ 1999. Identification of a Vibrio cholerae RTX toxin gene cluster that is tightly linked to the cholera toxin prophage. Proc Natl Acad Sci USA 96: 1071-1076.

Maslow JN, Slutsky AM, Arbeit RD 1993. Application of pulsedfield gel electrophoresis to molecular epidemiology. In DH Persing, TH Smith, FC Tenover, TJ White (eds), Diagnostic Molecular Microbiology: Principles and Applications, American Society for Microbiology, Washington, p. 563-572.

Merrell DS, Butler SM, Qadri F, Dolganov NA, Alam A, Cohen MB, Calderwood SB, Schoolnik GK, Camilli A 2002. Hostinduced epidemic spread of the cholera bacterium. Nature 417: 642-645.

Mitra R, Saha PK, Basu I, Venkataraman A, Ramakrishna BS, Albert MJ, Takeda Y, Nair GB 1998. Characterization of non-membrane-damaging cytotoxin of non-toxigenic Vibrio cholerae $\mathrm{O} 1$ and its relevance to disease. FEMS Microbiol Lett 169: 331-339.

Moustafa I, Connaris H, Taylor M, Zaitsev V, Wilson JC, Kiefel MJ, von Itzstein M, Taylor G 2004. Sialic acid recognition by Vibrio cholerae neuraminidase. J Biol Chem 279: 40819-40826.

Pal A, Saha PK, Nair GB, Yamasaki S, Takeda T, Takeda Y, Bhattacharya SK, Ramamurthy T 1999. Clonal analysis of nontoxigenic Vibrio cholerae $\mathrm{O} 1$ associated with an outbreak of cholera. Indian J Med Res 109: 208-211.

Roggentin P, Schauer R, Hoyer LL, Vimr ER 1993. The sialidase superfamily and its spread by horizontal gene transfer. $\mathrm{Mol}$ Microbiol 9: 915-921.

Sack DA, Sack RB, Nair GB, Siddique AK 2004. Cholera. Lancet 363: 223-233.

Salles CA, Momen H, Vicente AC, Coelho A 1993. Vibrio cholerae in South America: polymerase chain reaction and zymovar analysis. Trans R Soc Trop Med Hyg 87: 272.

Sambrook J, Fritsch EF, Maniatis T 1989. Molecular Cloning: a Laboratory Manual, 2nd ed., Cold Spring Harbor Laboratory Press, Cold Spring Harbor, NY. 
Sharma C, Thungapathra M, Ghosh A, Mukhopadhyay AK, Basu A, Mitra R, Basu I, Bhattacharya SK, Shimada T, Ramamurthy T, Takeda T, Yamasaki S, Takeda Y, Nair GB 1998. Molecular analysis of non-O1, non-O139 Vibrio cholerae associated with an unusual upsurge in the incidence of cholera-like disease in Calcutta, India. J Clin Microbiol 36: 756-763.

Staerk J, Ronneberger HJ, Wiegandt H 1974. Neuraminidase, a virulence factor in Vibrio cholerae infection? Behring Inst Mitt 55: 145-146.

Stewart-Tull DE, Ollar RA, Scobie TS 1986. Studies on the Vibrio cholerae mucinase complex. I. Enzymic activities associated with the complex. J Med Microbiol 22: 325-333.
Tauxe R, Seminario L, Tapia R, Libel M 1994. The Latin American Epidemic. In IK Wachsmuth, PA Blake, Ø Olsvik (eds), Vibrio cholerae and Cholera, American Society for Microbiology, Washington, p. 321-344.

Vimr ER, Troy FA 1985. Identification of an inducible catabolic system for sialic acids (nan) in Escherichia coli.J Bacteriol 164: 845-853.

Vimr ER, Kalivoda KA, Deszo EL, Steenbergen SM 2004. Diversity of microbial sialic acid metabolism. Microbiol Mol Biol Rev 68: 132-153.

Waldor MK, Mekalanos JJ 1996. Lysogenic conversion by a filamentous phage encoding cholera toxin. Science 272: 1910-1914. 